\title{
IGF-I/IGFBP-3 Equilibrates Ratios of Pro- to Anti-inflammatory Cytokines, Which Are Predictors for Organ Function in Severely Burned Pediatric Patients
}

\author{
Marc G. Jeschke, ${ }^{1,2}$ Robert E. Barrow, ${ }^{2}$ Fujiyo Suzuki, ${ }^{3}$ Jyoti Rai, $^{2}$ Deb Benjamin, ${ }^{2}$ \\ and David N. Herndon ${ }^{2}$ \\ ${ }^{1}$ University of Regensburg, Department of Surgery, Regensburg, Germany \\ ${ }^{2}$ Shriners Hospital for Children and Department of Surgery, University Texas Medical Branch, \\ Galveston, Texas, USA \\ ${ }^{3}$ Department of Internal Medicine, University of Texas Medical Branch, Galveston, Texas, USA \\ Accepted March 18, 2002
}

\begin{abstract}
Background: We hypothesized that ratios of pro- to antiinflammatory cytokines can be associated with hepatic, cardiac, and renal function after a severe trauma and can be used as predictors for clinical outcome. Furthermore, insulin-like growth factor-I (IGF-I) in combination with its principle binding protein (IGFBP-3) equilibrates proto anti-inflammatory cytokine ratios and improves homeostasis of severely burned pediatric patients.

Materials and Methods: Seventeen severely burned children were given a continuous infusion of IGF-I/BP-3 for 5 days after wound excision and grafting; seven were given saline during the same time period to serve as controls. Patient demographics and mortality were determined. Five days after excision and grafting, cardiac function was determined and blood samples were taken for serum levels of IGF-I, IGFBP-3, creatinine, pre-albumin, cholinesterase, pro-inflammatory cytokines (IL-1 $\beta$, IL-6, and TNF), and anti-inflammatory cytokines (IL-2, IL-4, IL-10 and IFN- $\gamma$ ).

Results: There were no differences between IGF-I/BP-3 and controls in age, gender, burn size, or mortality. Serum
\end{abstract}

IGF-I in burned children given the IGF-I/BP-3 complex increased from $102 \pm 15$ to $433 \pm 33 \mu \mathrm{g} / \mathrm{ml}$ and IGFBP-3 increased from $1.5 \pm 0.2$ to $3.0 \pm 0.2 \mu \mathrm{g} / \mathrm{ml}(p<0.05)$. Serum pre-albumin and cholinesterase increased with IGF-I/BP-3, whereas serum creatinine decreased when compared to controls $(p<0.05)$. IGF-I/BP-3 increased cardiac index by $16 \%$ and stroke volume index by $15 \%(p<0.05)$. These improvements in organ homeostasis were associated with decreased ratios of pro- to anti-inflammatory cytokines in the IGF-I/BP-3 group when compared to controls $(p<0.05)$.

Conclusions: Increased ratios of pro- to anti-inflammatory cytokines may indicate a higher risk for the incidence of multi-organ failure. We therefore suggest that ratios of pro-inflammatory to anti-inflammatory cytokines can be used to predict organ function. We further conclude that IGF-I/BP-3 equilibrates the balance between pro- and anti-inflammatory cytokines, which was associated with improved cardiac, renal, and hepatic function. The benefit of IGF-I/BP-3 in ameliorating the inflammatory response may also apply in reducing the multi-organ failure often observed in the state of severe trauma.

\section{Introduction}

Pro-inflammatory and anti-inflammatory cytokines are mediators of multiple events after trauma (1). They have been shown to be important factors in the genesis of immunomodulation, sepsis, shock, and acute phase response (2-4). The purpose of cytokine release is to restore homeostasis. Clinical studies, however, have shown that a sustained or increased release of pro-inflammatory cytokines, such as interleukin-1 (IL1), interleukin-6 (IL-6), or tumor necrosis factor (TNF) can contribute to multi-organ failure, hypermetabolism, morbidity, and mortality (5-9). Thus, the uncontrolled and prolonged action of pro-inflammatory

Correspondence and reprint requests should be addressed to: Marc G. Jeschke, MD, PhD, Klinikum der Universität Regensburg, Klinik und Poliklinik für Chirurgie, Franz-JosephStrauss-Allee 11, 93053 Regensburg, Germany. Phone: +941944-0; fax: +941-944-6965; e-mail: Mcjeschke@hotmail.com. cytokines is potentially dangerous (5-9). The physiologic counters of pro-inflammatory cytokines are antiinflammatory cytokines, such as interleukin-2 (IL-2), interleukin-4 (IL-4), interleukin-10 (IL-10), and interferon- $\gamma(\operatorname{IFN}-\gamma)(10,11)$. Anti-inflammatory cytokines are important signals in the cascade of the immune defense and equilibrate pro- and anti-inflammatory cytokines by decreasing pro-inflammatory cytokines $(10,11)$. IL-10 has particularly gained significance because its administration was associated with improved survival after LPS injection or induction of pancreatitis in rodents (11-13). Based on these findings that a decrease of anti-inflammatory cytokines and an increase of pro-inflammatory cytokines are associated with increased mortality, it seems evident that the balance between pro- and anti-inflammatory cytokines is crucial. We therefore suggest that a ratio of pro- to antiinflammatory cytokines is a measurment to determine the inflammatory cascade, and can predict organ 
function and thus clinical outcome. We determined pro-inflammatory cytokines (IL-1 $\beta$, IL-6, TNF), and anti-inflammatory cytokines (IL-2, IL-4, IL-10, IFN- $\gamma$ ), and then formed ratios of each cytokine. These ratios were associated with organ function, which was evaluated by measuring cardiac function, serum creatinine, and serum pre-albumin, cholinesterase for kidney and liver function, respectively.

Because decreased ratios of pro- to anti-inflammatory cytokines indicates improved organ function and clinical outcome, another purpose of the present study was to investigate whether an anabolic growth factor, we chose insulin-like growth factor-I (IGF-I), decreases the ratios of pro- to anti-inflammatory cytokines and therefore improves organ homeostasis. IGF-I is a 7.7-kDa single chain polypeptide of 70 amino acids with sequence homology to proinsulin (14). In the system 95-99\% of IGF-I is bound and transported with one of its six binding proteins (15). IGF-I has been shown to improve cell recovery, wound healing, peripheral muscle protein synthesis, and gut and immune function after thermal injury (16-20). Recent evidence suggests that IGF-I is instrumental in the early phases of liver regeneration after trauma and modulates the hepatic acute phase response in burned rats $(21,22)$. Deleterious side effects limited the clinical utilization of IGF-I; however, a new complex was recently developed in which IGF-I is bound in a 1:1 molar ratio to its principle binding protein IGFBP-3. This complex (IGF-I/BP-3) given in physiologic effective doses has been shown effective in thermally injured children and normal volunteers (20) without causing the adverse side effects of IGF-I, which are hypoglycemia, electrolyte imbalance, edema, neuropathies, and cardiac arrest $(17,23)$.

\section{Materials and Methods}

Twenty-four severely thermally injured children were randomly divided (block randomization 3:1) to receive recombinant human IGF-I in combination with its principle binding protein 3 (IGF-I/BP-3, $n=17$ ) or saline (control, $n=7$ ). Inclusion criteria were patients under 15 years of age, admission to our hospital within 2 days of injury without evidence of organ failure, and burns covering more than $40 \%$ total body surface area (TBSA) that required at least three operations for skin grafting.

The rhIGF-I/BP-3 complex was provided by Celtrix Pharmaceuticals, Inc. (Santa Clara, CA, USA) in a 1:1 molar ratio of rhIGF-I to rhIGFBP-3. This corresponds to the naturally occurring protein complex purified by cation exchange column chromatography. Infusions were prepared from vials containing $10 \mathrm{mg} / \mathrm{ml}$ rhIGF-I/BP-3 in sterile $50 \mathrm{mM}$ sodium acetate and $105 \mathrm{mM}$ sodium chloride buffered to $\mathrm{pH}$ 5.5.

\section{Study Design}

Patients were resuscitated according to the Galveston formula with $5000 \mathrm{cc} / \mathrm{m}^{2}$ TBSA burned $+2000 \mathrm{cc} / \mathrm{m}^{2}$
TBSA lactated Ringer's solution given in increments over the first 24 hours. Within 48 hours of admission, all patients underwent total burn wound excision, and the wounds covered with available autograft skin with allograft used to cover any remaining open areas. After the first operative procedure patients received $0.9 \%$ saline for 5-10 days until the donor site was healed, and were then taken back to the operation theater. In the two groups, blood samples were taken on postoperative day 5 . This study period was defined as study period I (Fig. 1) and its purpose was to insure that all patients had similar cytokine responses, hypermetabolism, and organ impairment.

Immediately after the second operation, patients were randomized into the treatment with a continuous intravenous infusion of either IGF-I/BP-3 in a dose of $1.0,2.0$, or $4.0 \mathrm{mg} / \mathrm{kg} / \mathrm{day}$ (drug, $n=17$ ) or $0.9 \% \mathrm{NaCl}$ (controls, $n=7$ ) until the donor site was healed. This was approximately 5-10 days after excision and grafting. Blood was again drawn on the fifth postoperative day (Fig. 1). This study period was defined as study period II.

Caloric intake in proteins, carbohydrates, and fat were measured and recorded each day. The amount of caloric intake was calculated for the study periods. All patients received nasoduodenal feedings with Vivonex TEN (Sandoz Nutrition, Minneapolis, MN, USA), containing $82.3 \%$ carbohydrate, $3 \%$ fat (linoleic acid), and $14.7 \%$ protein. Caloric intake was given at a rate calculated to deliver $1500 \mathrm{kcal} / \mathrm{m}^{2}$ TBSA burned $+1500 \mathrm{kcal} / \mathrm{m}^{2}$ TBSA. This feeding regimen was started at admission, and continued at a constant rate until the wound was $\mathbf{9 5 \%}$ healed. Caloric intake was kept constant and the same in both groups throughout the study period.

Serum IGF-I and IGFBP-3

Serum human IGF-I and human IGFBP3 were determined using a human radio immunoassay (Endocrine Sciences, Calabasas Hills, CA, USA).

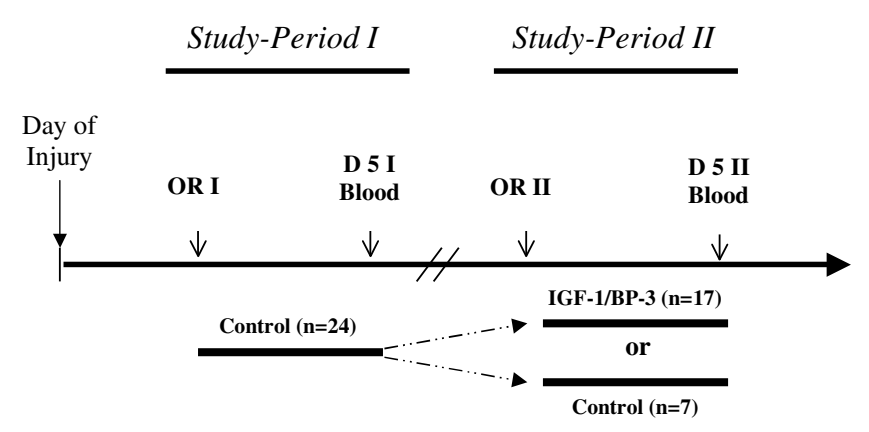

Fig. 1. Study protocol for all patients $(N=24)$ who underwent total burn wound excision within 48 hours of admission and were given $0.9 \%$ normal saline during study period I. Blood samples were taken 5 days after the operation (D 5 I). Patients were then randomized to the treatment with continuous intravenous infusion of either IGF-I/BP-3 $(n=17)$ or $0.9 \% \mathrm{NaCl}(n=7)$ for approximately 5 days after excision and grafting. Prior to (OP II) and 5 days after the second operative procedure (D 5 II) blood was again drawn. 


\section{Serum Creatinine, Pre-albumin, and Cholinesterase}

Serum creatinine as a parameter for the kidney, and serum pre-albumin and cholinesterase for the liver synthesis were determined by a Behring nephelometer (Behring, Darfield, IL, USA).

\section{Cardiac Function}

Cardiac 2-D ultrasound was used to obtain hemodynamics. Ultrasound was performed upon admission and during the second study period. The ultrasound measurements were performed by the same blinded observer for all patients. Parameters assessed were cardiac index (CI), stroke volume index (SVI), and left ventricular wall thickness (LVID) during systole and diastole. Rate pressure product mean arterial pressure times heart rate was used as an index of myocardial oxygen consumption.

\section{Serum Cytokines}

Plasma IL- $1 \beta$ and TNF levels were determined using an ELISA (Endogen, Woburn, MA, USA). Standard curves for quantification of human IL- $1 \beta$ or TNF were linear from $0-400 \mathrm{pg} / \mathrm{ml}$ or $0-200 \mathrm{pg} / \mathrm{ml}$ on a logarithmic scale, respectively. Serum levels of IL-6 were determined by a human ELISA (Biosource, Camarillo, CA, USA). Standard curves for quantification of human IL-6 were linear from $0-500 \mathrm{pg} / \mathrm{ml}$ on a logarithmic scale.

Peripheral blood mononuclear cells were isolated from heparinized peripheral blood. Whole blood was placed in a Ficoll-Hypaque density gradient centrifugation at $400 \mathrm{~g}$ for 30 minutes. The pellet was resuspended in a RPMI-1640 medium (10\% FBS, $2 \mathrm{mM}$ L-glutamine, $30 \mathrm{mM}$ HEPES, 5 M 2-mercaptoethanol, $100 \mathrm{U} / \mathrm{ml}$ penicillin, $100 \mu \mathrm{g} / \mathrm{ml}$ streptomycin). Mononuclear cells were then placed into a 24-well microtiter plate and were stimulated with $2.5 \mu \mathrm{g} / \mathrm{ml}$ of anti-CD3 monoclonal antibody for $48 \mathrm{hr}$ at $37^{\circ} \mathrm{C}$ in $5 \%$ carbon dioxide. ELISA were performed on the supernatants with antibodies for IL-2, IL-4, IL-10, and IFN- $\gamma$ (Pharmingen Inc, San Diego, CA, USA) on standard ELISA plates (Costar, Corning Incorporated, Corning, NY, USA).

\section{Ethics and Statistics}

Blood of healthy volunteers served to establish normal values. Informed consent approved by the Institutional Review Board of the University of Texas Medical Branch was obtained from all patients or parents. Statistical comparisons were made by paired $t$-test, ANOVA, and Student's $t$-test with post hoc Bonferroni's correction where appropriate. Data are expressed as means \pm SEM. Significance was accepted at $p<0.05$.

\section{Results}

In a dose-response, study we found that the complex given in a concentration of $0.5 \mathrm{mg} / \mathrm{kg} / \mathrm{day}$ had significantly fewer effects than the dose of $1-4 \mathrm{mg} / \mathrm{kg} /$ day. However, no significant differences between children receiving 1, 2, or $4 \mathrm{mg} / \mathrm{kg} /$ day of IGF-I/BP-3 could be shown in cytokine, creatinine, cholinesterase, and pre-albumin response; therefore, those patients were combined and treated as one group.

\section{Patient Demographics}

There were no significant differences in age, gender, size, or depth of burns or mortality between children treated with rhIGF-I/BP-3 or saline (Table 1). The age range for the control group was 2-10 years, the age range in the treatment group was 2-13 years. The body weight range was $12-30 \mathrm{~kg}$ in the control group and 11-46 kg in the treatment group. The ethnic backgrounds of the patients were similar in both groups (Americans, South Americans, African Americans).

There were no differences in caloric intake between the two patient groups and no differences between groups for times after burn to the admission to our hospital, to the start and end of study periods I and II (Table 1).

\section{Serum IGF-I and IGFBP-3}

Serum IGF-I and IGFBP-3 decreased after the burn trauma 3- to 4-fold below normal levels (Table 2). Although there was no change in serum IGF-I and IGFBP-3 in the burn control group, serum IGF-I significantly increased from $102 \pm 15 \mu \mathrm{g} / \mathrm{ml}$ to

Table 1. Patient characteristics and days postburn from admission to begin and end of the study periods

\begin{tabular}{lcc}
\hline & $\begin{array}{c}\text { Control } \\
\boldsymbol{n}=7\end{array}$ & $\begin{array}{c}\text { IGF-I/BP-3 } \\
\boldsymbol{n}=\mathbf{1 7}\end{array}$ \\
\hline Age (yrs) & $5.7 \pm 1.1$ & $6.2 \pm 0.8$ \\
$\begin{array}{l}\text { Gender (F/M) } \\
\text { Body weight (kg) }\end{array}$ & $45 \pm 3$ & $10 / 7$ \\
$\begin{array}{l}\text { Height (cm) } \\
\text { TBSA-burn (\%) }\end{array}$ & $109 \pm 11$ & $118 \pm 6$ \\
$\begin{array}{l}\text { 3rd degree-burn (\%) } \\
\text { Mortality (\%) }\end{array}$ & $59 \pm 4$ & $55 \pm 4$ \\
$\begin{array}{l}\text { Study periods } \\
\text { Hospital admission } \\
\quad \text { (days postburn) }\end{array}$ & $46 \pm 6$ & $46 \pm 6$ \\
$\begin{array}{l}\text { Start of study period I } \\
\text { (days postburn) }\end{array}$ & 17 & 0 \\
$\begin{array}{l}\text { End of study period I } \\
\quad \text { (days postburn) }\end{array}$ & $12 \pm 3$ & $7 \pm 3$ \\
$\begin{array}{l}\text { Start of study period II } \\
\quad \text { (days postburn) }\end{array}$ & $17 \pm 3$ & $14 \pm 3$ \\
$\begin{array}{l}\text { End of study period II } \\
\text { (days postburn) }\end{array}$ & $24 \pm 4$ & $19 \pm 3$ \\
\hline
\end{tabular}

Data presented as means \pm SEM. TBSA $=$ total body surface area. 
Table 2. Serum IGF-I and IGFBP-3, kidney and liver markers five days after the initiation of treatment or control

\begin{tabular}{|c|c|c|c|c|c|c|}
\hline & \multicolumn{3}{|c|}{$\begin{array}{c}\text { Control } \\
n=7\end{array}$} & \multicolumn{3}{|c|}{$\begin{array}{c}\text { IGF-I/BP-3 } \\
n=17\end{array}$} \\
\hline & D 5 I & D 5 II & $\Delta(\%)$ & D 5 I & D 5 II & $\Delta(\%)$ \\
\hline IGF-I $(\mu \mathrm{g} / \mathrm{ml})$ & $93 \pm 9$ & $103 \pm 13$ & $10 \pm 7$ & $102 \pm 15$ & $433 \pm 33 * \dagger$ & $382 \pm 44^{*}$ \\
\hline IGFBP-3 $(\mu \mathrm{g} / \mathrm{ml})$ & $1.4 \pm 0.2$ & $1.6 \pm 0.2$ & $3 \pm 8$ & $1.5 \pm 0.2$ & $3.0 \pm 0.2^{* \dagger}$ & $88 \pm 12^{*}$ \\
\hline Creatinine (mg/dl) & $3.3 \pm 0.5$ & $3.7 \pm 0.8$ & $5 \pm 3$ & $3.7 \pm 0.4$ & $2.3 \pm 0.2^{* \dagger}$ & $-20 \pm 9^{*}$ \\
\hline Pre-albumin (mg/dl) & $9 \pm 1$ & $11 \pm 1$ & $2 \pm 7$ & $11 \pm 1$ & $19 \pm 1^{* \dagger}$ & $55 \pm 9^{*}$ \\
\hline CHE (U/l) & $840 \pm 10$ & $870 \pm 15$ & $3 \pm 8$ & $800 \pm 15$ & $2200 \pm 30^{* \dagger}$ & $292 \pm 40^{*}$ \\
\hline
\end{tabular}

Data presented as means \pm SEM. $\Delta$ is defined as percent change from OP II to D 5 II.

* Significant difference IGF-I/BP-3 vs. control $(p<0.05) .{ }^{\dagger}$ Significant difference D 5 II vs. D 5 I $(p<0.05)$.

Values for unburned normal children:

IGF-I: $365 \pm 15 \mu \mathrm{g} / \mathrm{ml}$;

IGFBP-3: $2.8 \pm 0.9 \mu \mathrm{g} / \mathrm{ml}$;

Creatinine: $0.5-1.5 \mathrm{mg} / \mathrm{dl}$

Pre-albumin: $25-45 \mathrm{mg} / \mathrm{dl}$

CHE: $2400-8500 \mathrm{U} / \mathrm{l}$

$433 \pm 33 \mu \mathrm{g} / \mathrm{ml}(p<0.05)$ and serum IGFBP-3 from $1.5 \pm 0.2 \mu \mathrm{g} / \mathrm{ml}$ to $3.0 \pm 0.2 \mu \mathrm{g} / \mathrm{ml}(p<0.05)$ in the IGF-I/BP-3 group (Table 2).

\section{Serum Creatinine, Pre-albumin, and Cholinesterase}

Despite early and adequate resuscitation, burn caused a significant increase in serum creatinine, indicating kidney damage when compared with normal levels. In the burn control group, serum creatinine levels remained unchanged and elevated during the two study periods. In the IGF-I/BP-3 group, serum creatinine significantly decreased from $3.7 \pm 0.4 \mathrm{mg} / \mathrm{dl}$ at day 5 in the first study period to $2.3 \pm 0.2 \mathrm{mg} / \mathrm{dl}$ at day 5 in the second study period $(p<0.05)$.

After thermal injury, serum pre-albumin concentration decreased, indicating impaired hepatic constitutive hepatic protein synthesis. Serum pre-albumin concentration was 3- to 4-fold decreased in the burn control group and only showed a slight increased from study period I to study period II (Table 2). IGF-I/BP-3 treatment increased serum pre-albumin by $55 \%$ from study period I to study period II $(p<0.05$, Table 2$)$. Serum cholinesterase decreased after thermal injury, indicating hepatic impairment. Serum cholinesterase remained decreased in the burn control group, whereas IGFI/BP-3 increased cholinesterase to almost normal levels $(p<0.05$, Table 2$)$.

\section{Cardiac Function}

Cardiac index increased with the infusion of IGFI/BP-3 by $16 \pm 0.3 \%$, stroke volume index by $15 \pm$ $0.01 \%$ when compared to controls $(p<0.05)$. Because rate pressure product and left ventricular wall thick- ness did not change, myocardial oxygen consumption remained unchanged, thus indicating an improved cardiac function with IGF-I/BP-3 treatment.

\section{Serum Cytokines}

Burn caused an increase in the pro- and anti-inflammatory cytokines (IL-1 $\beta$, IL-6, TNF, IL-2, IL-4, IFN $\gamma$, and IL-10) measured in the present study when compared with normal levels. Cytokine concentrations remained nearly unchanged from study period I to study period II (Figs. 2 and 3). Furthermore, the ratios of pro- to anti-inflammatory cytokines were also found to be steady and did not demonstrate a decrease.

The administration of the IGF-I/BP-3 complex decreased TNF, but had no effect on the concentration of the pro-inflammatory cytokines IL- $1 \beta$ and IL-6 when compared with burn controls $(p<0.05)$. However, IGF-I/BP-3 increased the anti-inflammatory cytokines IL-2, IFN $\gamma$ and IL-10, when compared with burn controls $(p<0.05)$.

Despite the finding that IGF-I/BP-3 had no effect on serum IL-6 concentration, IGF-I/BP-3 significantly decreased the ratios of IL-6/IL-10, IL-6/IL-4, IL-6/IL2 , and IL-6/IFN $\gamma(p<0.05)$. These ratios approached values of normal levels, determined on normal healthy volunteers. There were no changes in the ratios of IL-6/IL-10, IL-6/IL-4, IL-6/IL-2, and IL-6/IFN $\gamma$ in the control group (Fig. 2). The ratios were elevated when compared with normal levels.

Although IGF-I/BP-3 had no effect on IL- $1 \beta$, IGF-I/BP-3 decreased the ratios of IL- $1 \beta / \mathrm{IL}-2$ and IL- $1 \beta / \mathrm{IFN}-\gamma$, thus values approached normal levels ( $p<0.05$, Fig. 3). Burn controls showed almost unchanged ratios. There were no effects of IGF-I/BP-3 
on the ratios of IL- $1 \beta / \mathrm{IL}-10$ and IL- $1 \beta / \mathrm{IL}-4$ when compared with controls.

IGF-I/BP-3 significantly decreased TNF concentrations during the study period $(p<0.05)$. In addition, IGF-I/BP-3 decreased the ratios of TNF/ IL-2 and TNF/IFN- $\gamma$; therefore, values approached normal levels ( $p<0.05$, Fig. 4). Burn controls showed almost unchanged ratios. The ratios TNF/IL-10 and TNF/IL-4 demonstrated each a $p$-value $<0.06$, but were not significantly different when compared with burned controls.

\section{Discussion}

Over the last decade, research has focused on the modulation of the inflammatory response in the state of trauma and sepsis. The use of antibodies against pro-inflammatory cytokines such as TNF, interleukin$1 \beta$ (IL- $1 \beta)$, or their receptors showed promising re- sults in vitro and in animal models by increasing survival rates in the state of septicemia $(2,24,25)$. However, when these approaches entered clinical trials, it became evident that these promising animal data could not be found in humans. A possible explanation that the anti-inflammatory agents used failed to control the exaggerated synthesis of pro-inflammatory cytokines may be that they focused on only one pathway or mediator in the inflammatory cascade leading to compensation through other pathways $(5,8,9)$. Another cause of the failure may have been that the anti-inflammatory cascade did not undergo intensive studies. It has not been until recently that investigations speculated about the importance of a balance between pro- and anti-inflammatory agents $(12,13)$. Two studies demonstrated that nonsurvivors with pancreatitis had increased IL-6 to IL-10 ratios when compared with survivors $(12,13)$. The relevance of cytokine ratios in the pathogenesis and the
A
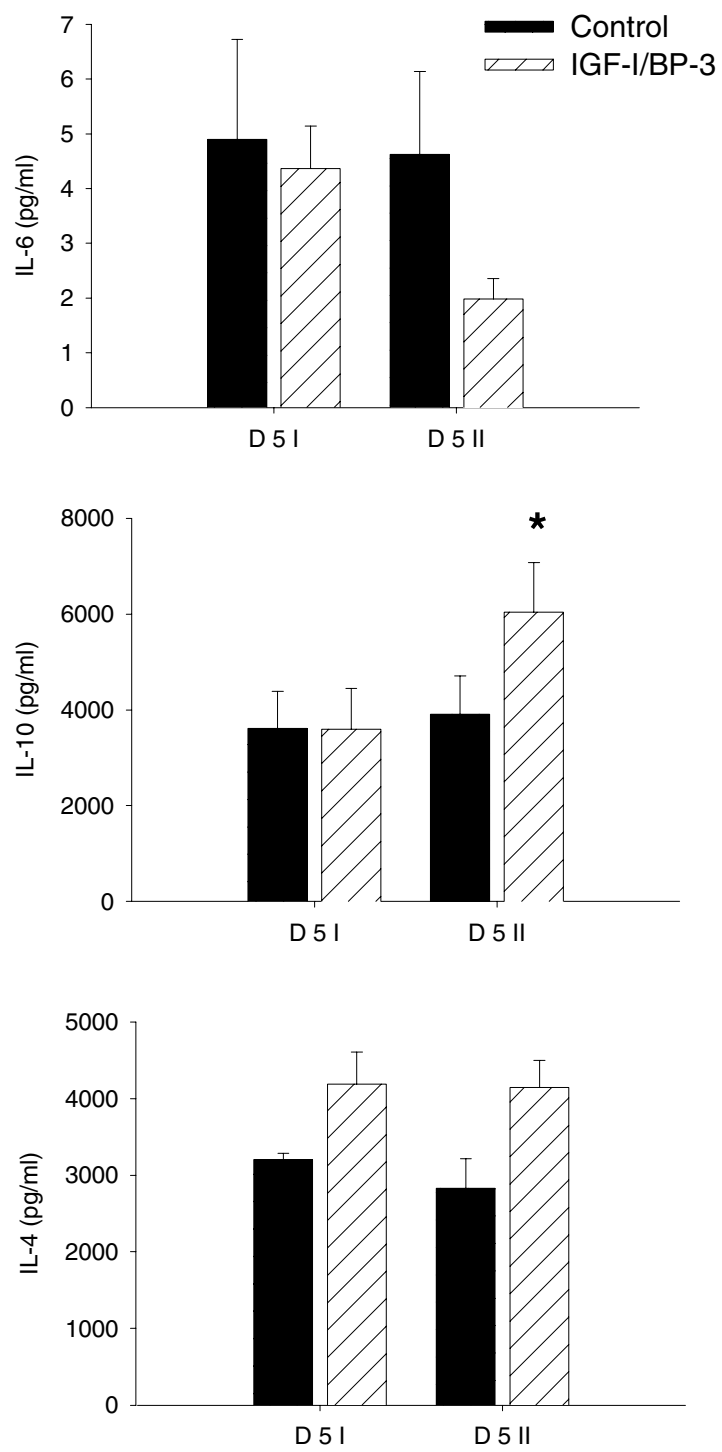

Fig. 2. (A) IL-6, IL-10, and IL-4 and their ratios. IGF-I/BP-3 decreased IL-6/IL-10 and IL-6/IL-4 and these ratios approached normal levels. Burn control patients demonstrated unchanged ratios of IL-6/IL-10 and IL-6/IL-4. *Significant difference between IGF-I/BP3 and control at D 5 II $(p<0.05)$. Data are presented as means \pm SEM. Normal values: IL-6/IL-10, 0.0005-0.0010; IL-6/IL-4, 0.00010-0.00025.

(B) IL-6, IL-2 and IFN- $\gamma$ and their ratios. IGF-I/BP-3 decreased IL-6/IL-2 and IL-6/IFN- $\gamma$ when compared to controls. These ratios approached normal levels. Control patients had an increase or no change in these ratios. *Significant difference between IGF-I/BP-3 and control at D 5 II $(p<0.05)$. Data are presented as means \pm SEM. Normal values: IL-6/IL-2, 0.0002-0.001; IL-6/IFN$\gamma, 0.0003-0.0010$.
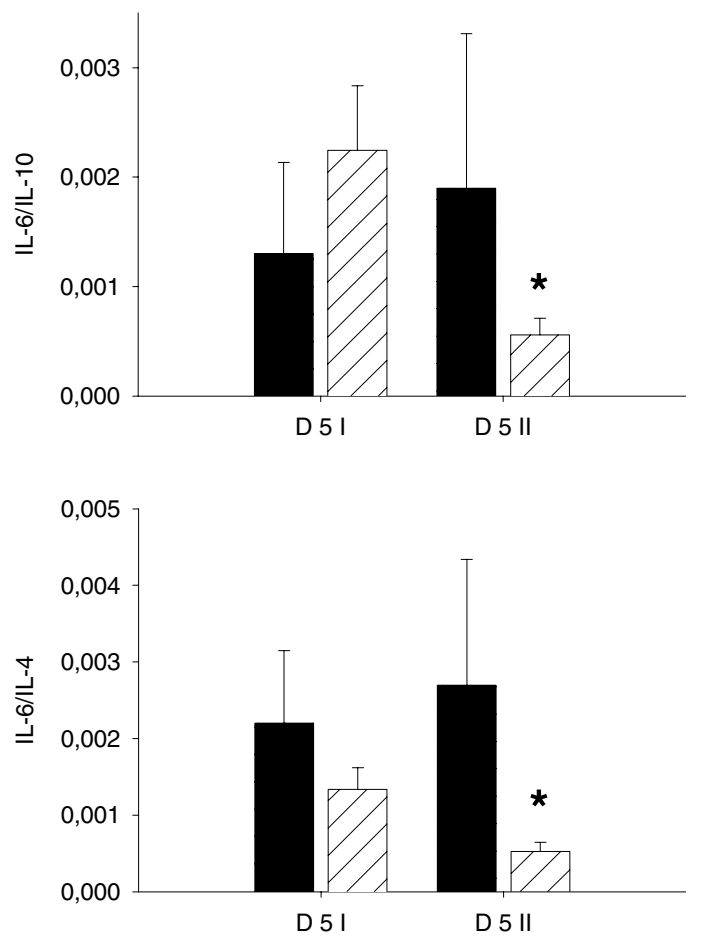

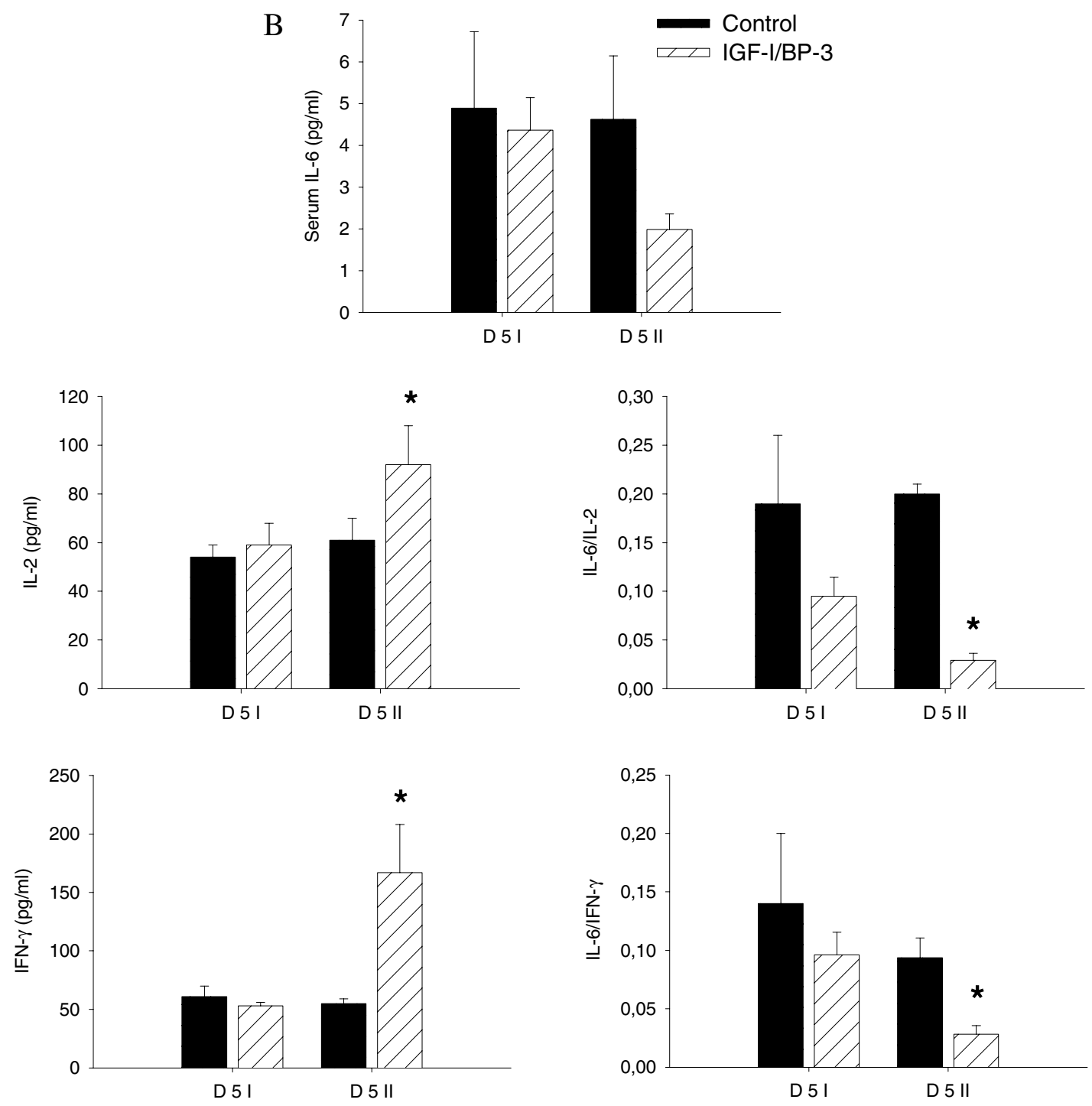

Fig. 2. (continued)

prediction of trauma, sepsis, and shock still need to be defined; however, individual effects have been investigated. A prolonged and increased inflammatory response contributes to multi-organ failure and mortality (5-7). The overexpression of pro-inflammatory cytokines, such as IL-1, IL-6, and TNF inhibit, the growth hormone-IGF-I axis and increase the hypermetabolic response with resulting increases in morbidity and mortality (26-28).

In contrast to pro-inflammatory cytokines, antiinflammatory cytokines appear to have protective characteristics. IL-2 and IFN- $\gamma$ are signals in the TH- 1 response and play a critical role in initiating and maintaining cellular immune responses, in the defense against of intracellular pathogens (29). IL-4 and IL-10 are TH-2 cytokines, characterized by production of B-cell-activating cytokines (29). TH-2 responses enhance the production of antibodies, which are crucial for the humoral immune response (e.g., in preventing disseminated infections). Administering IL-10 can protect against lethal doses of endotoxin in mice and decreases the release of endotoxin-induced IL- 6 and IL- $1(6,10,11)$. Thus, IL- 10 administration may ameliorate the endotoxemic shock and may improve survival. In the present study, we tested the hypotheses whether the ratio of pro- and anti-inflammatory cytokines could be associated with organ function and may predict survival, and whether a growth factor is able to affect these ratios and restore homeostasis. We demonstrated that IGF-I with its principle binding protein-3 restores the equilibrium between pro- and anti-inflammatory cytokines after severe thermal injury and that this shift is associated with improved liver, kidney, and muscle homeostasis. One has to mention that cytokine concentrations were very low. Therefore, it was very important to ensure that all samples were processed in an identical manner, in terms of separation, freezing, and analysis on 

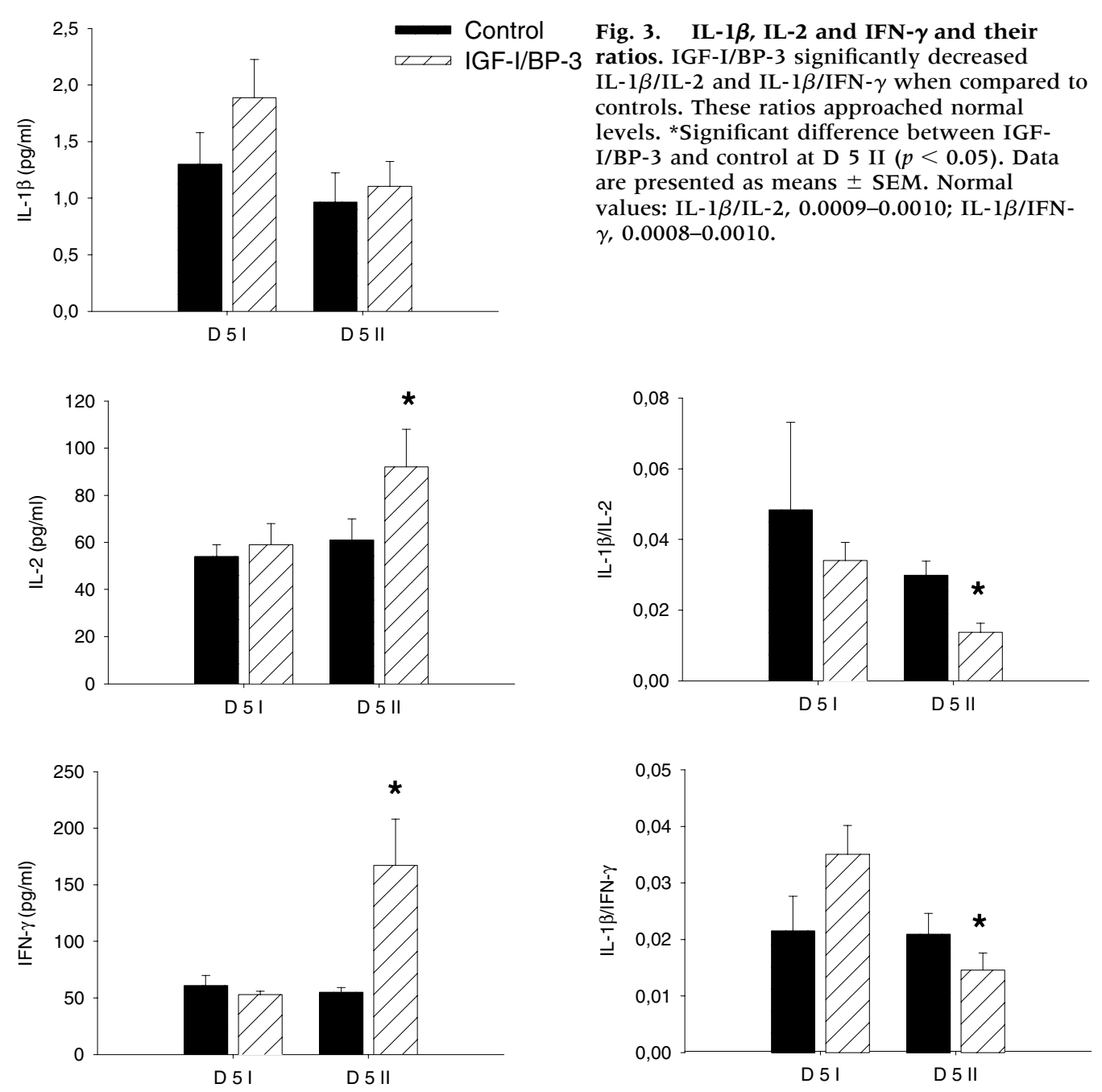

the same bench. Precautions were taken that all samples were treated the same and all at the same time.

The present study had two study periods. In the first, all patients underwent surgery and received saline infusions to ensure that all burned patients had similar cytokine response and organ impairment. The second period was the true study period, in which the effect of IGF-I/BP-3 was defined. Knowing that all patients had a similar hypermetabolic response during the first study period, all changes observed in the second study period were due to the IGF-I/BP-3 administration and not time effects. IGF-I is a 7.7-kDa single chain polypeptide of 70 amino acids with sequence homology to proinsulin (14). In the system, 95-99\% of IGF-I is bound and transported with one of its six binding proteins IGFBP 1-6 (15). The majority of IGF-I is bound to IGFBP-3. Administration of the IGF-I/BP-3 complex as a therapeutic agent provides several advantages over the administration of IGF-I alone, because when IGF-I is already bound to IGFBP-3, it rapidly transforms into a ternary complex that confers decreased serum clearance and it allows the delivery of significantly larger amounts of IGF-I without inducing hypoglycemia and electrolyte imbalances. In general, IGF-I has been shown to improve cell recovery, wound healing, peripheral muscle protein synthesis, and gut and immune function after thermal injury (17-20). Recent evidence suggests that IGF-I is instrumental in the early phases of liver regeneration after trauma and modulates the hepatic acute phase response in burned rats $(21,22)$. IGF-I furthermore improves renal function after trauma by preventing renal failure (30). The mechanisms by which IGF-I exerts its effects are not entirely defined; however, IGF-I appears to have antiapoptotic, pro-mitogenic effects on multiple cell lines, such as hepatocytes, small bowel epithelial cells, and hematopoietic progenitor cells $(21,30$, unpublished observations). Therefore, IGF-I seems to affect extra- and intracellular signaling pathways. Recent studies demonstrated that IGF-I is capable of modulating the CCCAT-enhancer binding protein (C/EBP) family (31-34). IGF-I decreases the C/EBP $\beta$ subtype, which increases after trauma and regulates cytokine and protein synthesis $(31,32)$. In contrast, 


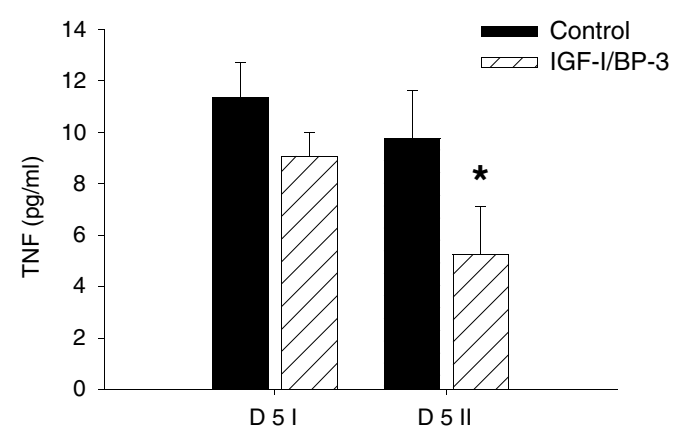

Fig. 4. TNF, IL-2 and IFN- $\gamma$ and their ratios. IGF-I/BP-3 significantly decreased TNF at D 5 II when compared to burned controls $(p<0.05)$ that demonstrated no change in TNF. Furthermore, IGF-I/BP-3 significantly decreased ratios of TNF/IL-2 and TNF/IFN- $\gamma$ compared to burn controls that demonstrated no change over the two study periods. With the administration of IGF-I/BP-3 the ratios of TNF/IL-2 and TNF/IFN- $\gamma$ approached ratios of normal controls. *Significant difference between IGF-I/BP-3 and control at D 5 II $(p<0.05)$. Data are presented as means \pm SEM. Normal values: TNF/IL-2, 0.003-0.005; TNF/IFN- $\gamma$, 0.005-0.007.
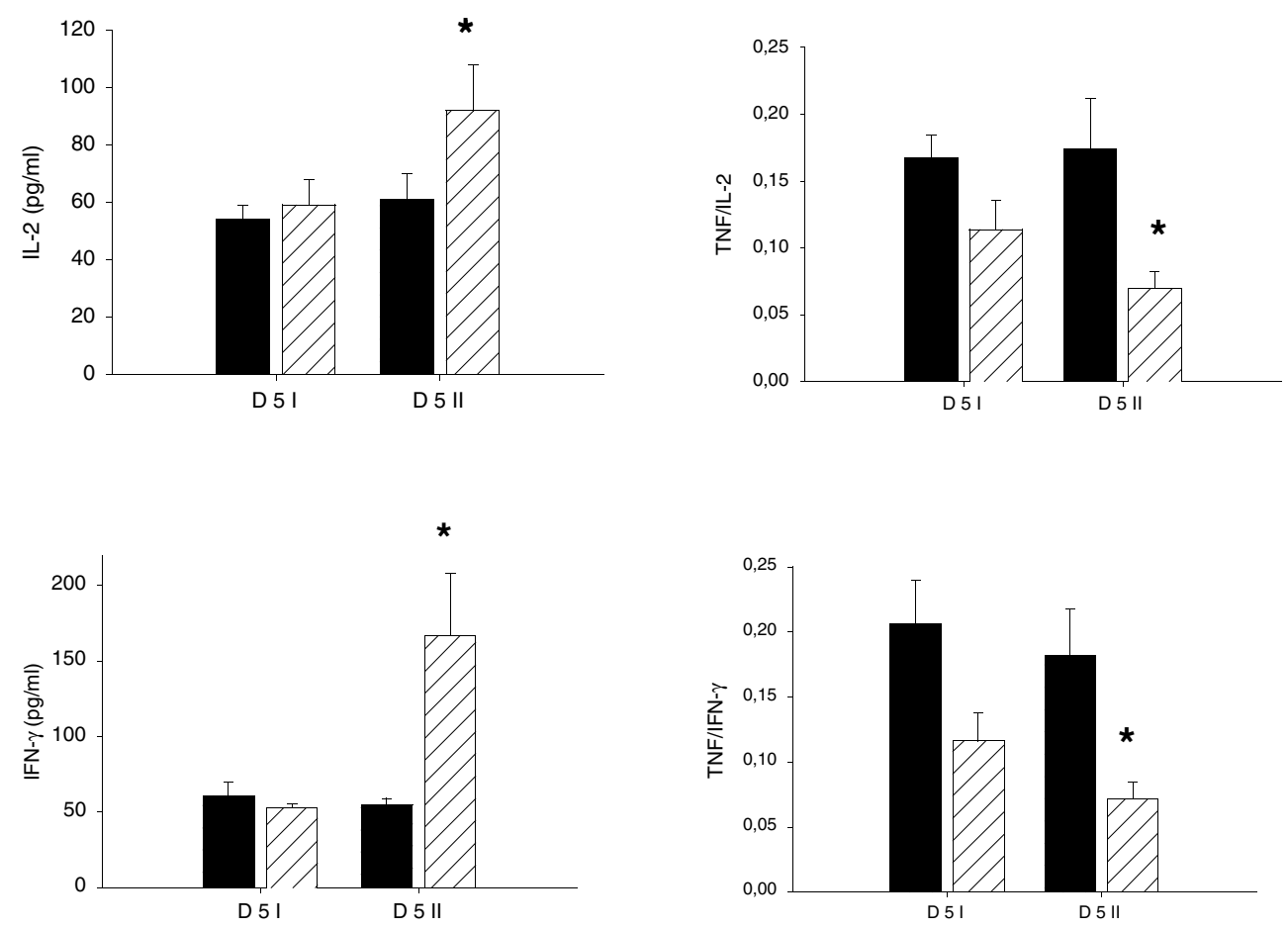

IGF-I increases the C/EBP $\alpha$ subtype, which decreases after trauma and regulates constitutive hepatic protein synthesis $(31,35)$. IGF-I has furthermore been shown to affect nuclear factor- $\kappa \mathrm{B}(\mathrm{NF}-\kappa \mathrm{B})$. NF- $\kappa \mathrm{B}$ controls the transcriptional regulation of many pro-inflammatory cytokines and acute phase proteins that contain NF- $\kappa$ B response elements in their promoter region $(3,36-38)$. IGF-I further affects nitric oxide, JAK/STAT, Gp 130, and many more transcription and translation factors $(35,36)$. We therefore suggest that IGF-I plays a major role after trauma by maintaining organ homeostasis and function.

In the present study, we did not differentiate between survivors and nonsurvivors; our patient population was too small and only one control patient died. However, we associated the ratios of pro- and anti-inflammatory cytokines with renal and hepatic function. We found that decreased ratios of pro- and anti-inflammatory cytokines were associated with improved renal and hepatic function. In another study, we de- termined in the same patient population peripheral muscle protein synthesis, measured as fractional synthetic rate by stable isotope technique (20). We found that children treated with the IGF-I/BP-3 complex showed increased peripheral muscle protein synthesis 5 days after the administration of the drug when compared with controls (20). These findings suggest that an attenuation of pro- and anti-inflammatory cytokines is not only associated with kidney and liver function, but also with increased systemic protein synthesis or decreased protein catabolism.

Because unpublished findings by our group demonstrated a significantly decreased amount of ventilator days in the IGF-I/BP-3 group, we suggest that an exaggerated pro-inflammatory and a decreased anti-inflammatory response leads to increased ratios of pro-inflammatory to anti-inflammatory cytokines may indicate a higher risk for the incidence of multiorgan failure and worse clinical outcome. We therefore hypothesize that ratios of pro-inflammatory to 
anti-inflammatory cytokines can be used to predict clinical outcome and should be included in clinical studies. Although we tested this hypothesis in thermally injured children, we propose that these ratios are applicable to other forms of trauma. We further conclude that IGF-I/BP-3 equilibrates the balance between pro- and anti-inflammatory cytokines, which was associated with improved cardiac, renal, and hepatic function. The benefit of IGF-I/BP-3 in ameliorating the inflammatory response may also apply in reducing multi-organ failure and mortality often observed in the state of severe trauma.

\section{Acknowledgment}

This study was supported by the Shriners Hospital for Children, Grant \#8660 and 8490, NIH Grants 1 ROl-GM56687-01 and 5 T32 GM 0825607, and Celtrix Pharmaceutical Company.

\section{References}

1. Pinsky MR, Vincent JL, Deviere J. (1993) Serum cytokine levels in human septic shock: relation to multiple system organ failure and mortality. Chest 103: 565-575.

2. Tracey KJ, Fong Y, Hesse DG, et al. (1987) Anti-cachectin/ TNF monoclonal antibodies prevent septic shock during lethal bacteraemia. Nature 330: 662-664.

3. Moshage H. (1997) Cytokines and the hepatic acute phase response. J. Pathol. 181: 257-266.

4. Jeschke MG, Wolf SE, DebRoy MA, Herndon DN. (1999) The combination of growth hormone with hepatocyte growth factor alters the acute phase response. Shock 12: 181-187.

5. Livingston DH, Mosenthal AC, Deitch EA. (1995) Sepsis and multiple organ dysfunction syndrome: a clinical-mechanistic overview. New Horizons 3: 276-287.

6. Selzman CH, Shames BD, Miller SA, et al. (1998) Therapeutic implications of interleukin-10 in surgical disease. Shock 10: 309-318.

7. De Maio A, de Mooney ML, Matesic LE, Paidas CN, Reeves RH. (1998) Genetic component in the inflammatory response induced by bacterial lipopolysaccharide. Shock 10: 319-323.

8. Pruitt JH, Copeland EM, Moldawer LL. (1995) Interleukin-1 and interleukin- 1 antagonism in sepsis systemic inflammatory response syndrome and septic shock. Shock 3: 235-251.

9. Williams G, Giroir B. (1995) Regulation of cytokine gene expression: tumor-necrosis factor, interleukin-1, and the emerging biology of cytokine receptors. New Horizons 2: 276-287.

10. de Waal Malefyt R, Abrams J, Bennett B. (1991) Interleukin 10 (IL-10) inhibits cytokine synthesis by human monocytes: an autoregulation role of IL-10 produced by monocytes. J. Exp. Med. 174: 1209-1220.

11. Kusske AM, Rongione AJ, Reber HA. (1996) Cytokines and acute pancreatitis. Gastroenterology 110: 639-642.

12. Taniguchi T, Koido Y, Aiboshi J, Yamashita T, Suzaki S, Kurokawa A. (1999) Change in the ratio of interleukin-6 to interleukin-10 predicts a poor outcome in patients with systemic inflammatory response syndrome. Crit. Care Med. 27: 1262-1264.

13. Simovic MO, Bonham MJ, Abu-Zidan FM, Windsor JA. (1999) Anti-inflammatory cytokine response and clinical outcome in acute pancreatitis. Crit. Care Med. 27: 2662-2665.

14. Humbel RE. (1990) Insulin-like growth factor-I and factor-II. Eur. J. Biochem. 190: 445-462.

15. Baxter RC. (1990) Circulating levels and molecular distribution of the acid-labile (alpha) subunit of the high molecular weight insulin-like growth factor-binding protein complex. J. Clin. Endocrinol. Metab. 70: 1347-1353.

16. Clemmons DR. (1994) Insulin-like growth factor- 1 as an anabolic agent in catabolic states. Ann Intern Med 120: 596-597.
17. Bondy CA, Underwood LE, Clemmons DR. (1994) Clinical uses of insulin-like growth factor-I. Ann. Intern. Med. 120: 593-601.

18. Huang KF, Chung DH, Herndon DN. (1993) Insulin-like growth factor-1 (IGF-I) reduces gut atrophy and bacterial translocation after severe burn injury. Arch. Surg. 128: 47-54.

19. Steenfos HH. (1994) Growth factors and wound healing. Scand. J. Plast. Reconstr. Hand Surg. 28: 95-105.

20. Herndon DN, Ramzy PI, DebRoy MA, Wolf SE. (1999) Effects of insulin-like growth factor in combination with insulinlike growth factor binding protein-3 in severely burned children. Ann. Surg. 229: 713-720.

21. Michelopoulos GK, DeFrances M. (1997) Liver regeneration. Science 276: 60-66.

22. Jeschke MG, Herndon DN, Barrow RE. (2000) Insulin-like growth factor I in combination with insulin-like growth factor binding protein 3 affects the hepatic acute phase response and hepatic morphology in thermally injured rats. Ann. Surg. 231: 408-416.

23. Jabri N, Schalch DS, Schwartz SL. (1994) Adverse effects of recombinant human insulin-like growth factor-I in obese insulin-resistant type II diabetic patients. Diabetes 43: 369-374.

24. Beutler B, Milsark IW, Cerami AC. (1985) Passive immunization against cachectin/tumor necrosis factor protects mice from lethal effect of endotoxin. Science 229: 869-871.

25. Alexander HR, Doherty GM, Buresh CM. (1991) A recombinant human receptor antagonist to interleukin 1 improves survival after lethal endotoxemia in mice. J. Exp. Med. 173: 1029-1032.

26. Thissen JP, Verniers J. (1997) Inhibition by interleukin- $1 \beta$ and tumor necrosis factor- $\alpha$ of the insulin-like growth factor I messenger ribonucleic acid response to growth hormone in rat hepatocyte primary culture. Endocrinology 138: 1078-1084.

27. Lang CH, Fan J, Cooney R, Vary TC. (1996) IL-1 receptor antagonist attenuates sepsis-induced alterations in the IGF system and protein synthesis. Am. J. Physiol. 270: E430- E437.

28. Delhanty PJ. (1998) Interleukin-1 beta suppresses growth hormone-induced acid-labile subunit mRNA levels and secretion in primary hepatocytes. Biochem. Biophys. Res. Commun. 243: 269-272.

29. Salgame P, Abrams JS, Clayberger C, et al. (1991) Differing lymphokine profiles of functional subsets of human CD4 and CD8 T cell clones. Science 254: 279-282.

30. Kelley KW, Meier WA, Minshall C, et al. (1998) Insulin growth factor-I inhibits apoptosis in hematopoietic progenitor cells. Implications in thymic aging. Ann. N.Y. Acad. Sci. 840: 518-524.

31. Gilpin DA, Hsieh CC, Kuninger DT, Herndon DN, Papaconstantinou J. (1996) Effect of thermal injury on the expression of transcription factors that regulate acute phase response genes: the response of $\mathrm{C} / \mathrm{EBP} \alpha, \mathrm{C} / \mathrm{EBP} \beta$, and $\mathrm{C} / \mathrm{EBP} \delta$ to thermal injury. Surgery 119: 674-683.

32. Alam T, An MR, Papaconstantinou J. (1992) Differential expression of three C/EBP isoforms in multiple tissues during the acute phase response. J. Biol. Chem. 267: 502 1-5024.

33. Umayahara Y, Ji C, Centrella M, Rotwein P, McCarthy TL. (1997) CCAAT/enhancer-binding protein delta activates insulin-like growth factor-I gene transcription in osteoblasts. Identification of a novel cyclic AMP signaling pathway in bone. J. Biol. Chem. 272: 31793-31800.

34. Nolten LA, Steenbergh PH, Sussenbach JS. (1995) Hepatocyte nuclear factor 1 alpha activates promoter 1 of the human insulin-like growth factor I gene via two distinct binding sites. Mol. Endocrinol. 9: 1488-1499.

35. Nolten LA, van Schaik FM, Steenbergh PH, Sussenbach JS. (1994) Expression of the insulin-like growth I gene is stimulated by the liver-enriched transcription factors C/EBP alpha and LAP. Mol. Endocrinol. 8: 1636-1645.

36. Siebenlist U, Franzoso G, Brown K. (1994) Structure, regulation and function of NF- $\kappa$ B. Annu. Rev. Cell Biol. 10: 405-455.

37. Dinarello CA. (1996) Biologic basis for interleukin-1 in disease. Blood 87: 2095-2147.

38. Kishimoto T, Taga T, Akira S. (1994) Cytokine signal transduction. Cell 76: 325-328. 